OPEN ACCESS

Edited by:

Billy Sperlich,

Universität Würzburg, Germany

Reviewed by:

Giovanni Messina,

University of Foggia, Italy

Henning Bay Nielsen,

University of Copenhagen, Denmark

*Correspondence:

Rafael R. Lima

rafalima@ufpa.br

tThese authors have contributed equally to this work.

Specialty section: This article was submitted to

Exercise Physiology,

a section of the journal

Frontiers in Physiology

Received: 05 December 2017

Accepted: 14 May 2018

Published: 08 June 2018

Citation:

Fernandes RM, Correa MG, dos

Santos MAR, Almeida APCPSC,

Fagundes NCF, Maia LC and Lima RR

(2018) The Effects of Moderate

Physical Exercise on Adult Cognition:

A Systematic Review.

Front. Physiol. 9:667

doi: 10.3389/fphys.2018.00667

\section{The Effects of Moderate Physical Exercise on Adult Cognition: A Systematic Review}

\author{
Rafael M. Fernandes ${ }^{1 \dagger}$, Marcio G. Correa ${ }^{1 \dagger}$, Marcio A. R. dos Santos ${ }^{2}$, \\ Anna P. C. P. S. C. Almeida ${ }^{1}$, Nathália C. F. Fagundes ${ }^{1}$, Lucianne C. Maia ${ }^{3}$ and \\ Rafael R. Lima ${ }^{1 *}$ \\ ${ }^{1}$ Laboratory of Functional and Structural Biology, Institute of Biological Sciences, Federal University of Pará, Belém, Brazil, \\ ${ }^{2}$ Nucleus of Transdisciplinary Studies in Basic Education, Federal University of Pará, Belém, Brazil, ${ }^{3}$ Pediatric Dentistry and \\ Orthodontics, Federal University of Rio de Janeiro, Rio de Janeiro, Brazil
}

Background: Physical exercise is a systematic sequence of movements executed with a predefined purpose. This muscular activity impacts not only on circulatory adaptations, but also neuronal integration with the potential to influence cognition. The aim of this review was to determine whether the literature supports the idea that physical exercise promotes cognitive benefits in healthy adults.

Methods: A systematic search for relevant articles was performed according to the Preferred Reporting Items for Systematic Review and Meta-Analysis criteria using available databases (PubMed, LILACS, Scopus, Web of Science, The Cochrane Library, OpenGrey, Google Scholar and CENTRAL). The search terms included "humans" or "adults" or "cognition" or "awareness" or "cognitive dissonance" or "cognitive reserve" or "comprehension" or "consciousness" and "motor activity" or "exercise" or "physical fitness," and not "aged" or "nervous system diseases," with the purpose of finding associations between moderate physical exercise and cognition. A methodological quality and risk of bias unit assessed the eligibility of articles.

Results: A total of 7179 articles were identified. Following review and quality assessment, three articles were identified to fulfill the inclusion criteria. An association between moderate physical exercise and cognition was observed. Improvements in cognitive parameters such as reduced simple reaction time, improved response precision and working memory were identified among the included articles.

Conclusion: This systematic review found that moderate physical exercise improves cognition.

Keywords: moderate physical exercise, cognition, reaction time, physical activity, physical exercise

\section{INTRODUCTION}

Physical exercise consists of a systematic sequence of movements executed with a predefined purpose (American College of Sports Medicine, 2009; Bowden et al., 2011) and is described by its effect on oxygen consumption as a percentage of maximum oxygen consumption $\left(\mathrm{VO}_{2} \max \right)$ (Barstow et al., 1990; Drummond et al., 2005). The concept of physical exercise is a subcategory 
of physical activity (Caspersen et al., 1985). Since the seminal paper by Morris and Crawford (1958) which evaluated health in bus drivers, several papers have reported an association between regular exercise activity and a reduced risk for the development of cancer and cardiovascular disease. However, its effect on brain function seems less explored.

Neuronal integration involves multiple cognitive functions and neuronal networks, including work memory and spatial memory (Tucker and Stern, 2011; Moon et al., 2017). Both neurons and astrocytes need a constant supply of nutrients (glucose and lactate) and oxygen, and regional cerebral oxygenation may be limited during exercise (Nielsen et al., 1999; Rooks et al., 2010; Braz and Fisher, 2016) with a change in the balance of cerebraI metabolism (Avola et al., 2004; Dalsgaard and Secher, 2007; van Hall et al., 2009). In addition, specific neurotrophic growth factors seem to be released as a result of moderate physical exercise, which increases the expression of brain-derived neurotrophic factor (BDNF) and neuronal growth factor (NGF) (Tyler and Pozzo-Miller, 2003; Dietrich et al., 2008; Seifert et al., 2010; Bonini et al., 2013; Coelho et al., 2014; Hashimoto et al., 2018). These factors contribute to increased cell survival and differentiation, as well as resistance to oxidative stress (Dietrich et al., 2008; Coelho et al., 2014). Furthermore, they can modulate neuroplasticity with an effect on brain function (Erickson et al., 2013). Another possible brain mechanism mediated by physical exercise could be related to the orexin system, increasing the release of orexin and orexin b. These are neuropeptides that modulate synaptic plasticity, neurogenesis, and cognition (Chieffi et al., 2017b,c).

Physical exercise may influence an individual's cognitive ability through its integrative effect on circulation and cerebral activity (van den Berg et al., 2016; Best et al., 2017); however, the scientific literature on this topic is limited. This systematic review aims to find evidence pointing to the effects of moderate physical exercise on cognitive functions in healthy adults.

\section{MATERIALS AND METHODS}

\section{Study Design}

A systematic review was conducted according to the Preferred Reporting Items for Systematic Review and Meta-Analysis (PRISMA) guidelines (Moher et al., 2009). The review was registered in PROSPERO, the international prospective register of systematic reviews (CRD42016049663).

\section{Participants, Interventions, and Comparators}

This research followed the PICO strategy, as recommended by PRISMA group (Moher et al., 2009), to develop the search criteria and determine which relevant articles to include or exclude. Interventional studies focused on the effects of moderate physical exercise on healthy adults were included, presented in Table $\mathbf{1 .}$

\section{Systematic Review Protocol}

Two evaluators (MGC and RMF) performed an independent search, evaluated the validity of the publications and extracted duplicates of documents. The studies were evaluated based on the
TABLE 1 | Inclusion criteria following the PICOS strategy (Moher et al., 2009).

\begin{tabular}{ll}
\hline Inclusion Criteria & \\
\hline P (participants) & Healthy humans at any age \\
I (intervention) & Physical activity \\
C (comparison) & Absence of Physical activity \\
$\mathrm{O}$ (Outcome) & Primary outcome: Changes is cognition \\
& Secondary outcome: Correlation or association \\
& of another aspects, such as age, gender, \\
& previous history of smoking, alcohol, and body \\
& mass index in cognition outcome \\
S (type of studies included) & Studies of intervention
\end{tabular}

relevance of their titles and abstracts, and those that did not meet the PICO criteria were excluded. The evaluators then read the full-text versions of the selected articles. In case of disagreement, the two authors would give a joint evaluation. If any doubt remained, a third member of the research team was consulted (NCFF).

All articles that met the study requirements were included in this review. The exclusion criteria included in vitro experiments, literature reviews, laboratory animal studies, letters to the editor, case reports, opinions and guides. Studies that did not include cognitive tests were also excluded.

\section{Search Strategy}

Electronic searches were conducted in eight databases: PubMed, LILACS, Scopus, Web of Science, The Cochrane Library, OpenGrey, Google Scholar, The Cochrane Library and the The Cochrane Central Register of Controlled Trials (CENTRAL). Studies that investigated the effect of physical activity on the cognition of adult individuals without any central nervous system disorders or diseases (Supplementary Material) were included.

At the end of the search, alerts were created in each of the databases to identify any further references that could be included in this study. We also searched the references in the selected articles to find articles that met the search categories but had not been found in the selected databases. All reference records were imported to a reference manager software (EndNote X7, Thomas Reuters, Philadelphia, USA).

\section{Selection of Studies and Data Extraction}

After the importation of the searches, the duplicated results were removed. The selection process was performed in two phases. The first phase includes an evaluation of tittles and abstracts according to PICO strategy (Table 1). In the phase two, the remaining articles were evaluated by full text according to the same criteria. The searches and selection process were conducted by two examiners (MGC and RMF) and checked by a third examiner (NCFF), in cases of disagreements.

After this phase, the data extraction of the included studies was performed. The data regarding the type of study, objective, sample characteristics, physical training, cognitive test, and main results were included in a table. In case of absence of information that makes data extraction or risk of bias evaluation impracticable, we attempted to contact the authors by e-mail. 
The contact consisted in sending a weekly email, for up to five consecutive weeks.

\section{Risk of Bias}

The same evaluators also independently analyzed the methodological quality of all articles. Randomized trials were evaluated according to the Cochrane Collaboration's Risk of Bias tool. This tool evaluates the risk of bias as "low," "high," or "unclear" (Higgins et al., 2011) according to the items described in Table 2.

For non-randomized studies, the Methodological Index for Non-Randomized Studies (MINORS) was used (Slim et al., 2003). This ranked the articles according to a list of 12 items, and each reviewer scored the articles according to a standard checklist where a score of 0 represented "not reported," 1 was "reported but inadequate" and 2 was "reported and suitable" for the items described in Table 3.

The quality of the article was evaluated by the sum of the values obtained in the MINORS qualifier, with a score of 0-6 indicating very low quality, 7-12 low quality, 13-18 moderate quality and 19-24 representing high quality (Khan et al., 2015).

\section{RESULTS}

\section{Description of Studies}

There were a total of 7,179 citations about this topic identified in the different databases. Scopus had the most ( $n=3,666)$, followed by Central Register of ControlledCENTRAL $(n=2,027)$, Lilacs $(n=654)$, Web of Science $(n=430)$, PubMed $(n=300)$, Cochrane Library $(n=76)$, Google Scholar $(n=26)$ then finally OpenGrey $(n=0)$. Figure 1 summarizes the study selection process. From the 7,179 citations, 414 duplicates were withdrawn and 6,765 remained.

A total of 155 papers were selected according to their title and abstract, of which seven (Biddle and Ashford, 1988; Brown et al., 1995; Bue-Estes et al., 2008; Douw et al., 2014; Lee et al., 2014; Tsai et al., 2014; Olson et al., 2016) were chosen based on the eligibility criteria for full-text reading. Four articles were excluded, two (Douw et al., 2014; Lee et al., 2014) were excluded due to the absence of a control group, and the other two (Biddle and Ashford, 1988; Brown et al., 1995) due to the absence of specific cognition tests. Three articles (Bue-Estes et al., 2008; Tsai et al., 2014; Olson et al., 2016) were selected and submitted to a qualitative synthesis.

\section{Study Selection and Characteristics}

The main characteristics of the included articles are listed in Table 4. In the three studies there was an association between moderate physical exercise and cognition. While the included articles each used a different evaluation tool, they all evaluated reaction time as a common parameter to measure cognition. Reaction time is the time elapsed between a stimuli and the response. Each study showed a positive correlation between moderate physical exercise by a different parameter improvement as tested by the following methods: Automated neuropsychological assessment metrics, which evaluates the reaction time, memory, attention, concentration, thinking speed
TABLE 2 | Criteria for risk assessment of bias according to "The Cochrane Collaboration's tool for assessing risk of bias (Higgins et al., 2011).

\begin{tabular}{|c|c|}
\hline \multicolumn{2}{|c|}{ RANDOM SEQUENCE GENERATION } \\
\hline $\begin{array}{l}\text { Criteria for judgment of } \\
\text { "Low risk" of bias }\end{array}$ & $\begin{array}{l}\text { The articles that appropriately described the } \\
\text { method of randomization }\end{array}$ \\
\hline $\begin{array}{l}\text { Criteria for judgment of } \\
\text { "High risk" of bias }\end{array}$ & $\begin{array}{l}\text { Articles that presented a methodological failure } \\
\text { in the randomization criterion or the difficult } \\
\text { reproducibility method }\end{array}$ \\
\hline $\begin{array}{l}\text { Criteria for judgment of } \\
\text { "Unclear" of bias }\end{array}$ & $\begin{array}{l}\text { When the articles did not describe the method } \\
\text { of randomization }\end{array}$ \\
\hline \multicolumn{2}{|c|}{ ALLOCATION CONCEALMENT } \\
\hline $\begin{array}{l}\text { Criteria for judgment of } \\
\text { "Low risk" of bias }\end{array}$ & $\begin{array}{l}\text { When the allocation sequence of samples were } \\
\text { concealed in the randomization }\end{array}$ \\
\hline $\begin{array}{l}\text { Criteria for judgment of } \\
\text { "High risk" of bias }\end{array}$ & $\begin{array}{l}\text { When the sequence of allocation of samples } \\
\text { were not concealed at randomization }\end{array}$ \\
\hline $\begin{array}{l}\text { Criteria for judgment of } \\
\text { "Unclear risk" of bias }\end{array}$ & $\begin{array}{l}\text { When the allocation sequences were } \\
\text { unreported }\end{array}$ \\
\hline
\end{tabular}

Criteria for judgment of

When the sample was blind

"Low risk" of bias

Criteria for judgment of

"High risk" of bias

If the methodology could not be blinded for whatever reason (sample/appraiser)

Criteria for judgment of

"Unclear risk" of bias

When the sample was not reported either way

\section{BLINDING OF OUTCOME ASSESSMENT}

$\begin{array}{ll}\text { Criteria for judgment of } & \text { When the evaluators reported that the blinding } \\ \text { "Low risk" of bias } & \text { in the evaluation was effective } \\ \text { Criteria for judgment of } & \text { If the study informed the evaluators how the } \\ \text { "High risk" of bias } & \text { blinding was done } \\ \text { Criteria for judgment of } & \text { When the blinding was not reported }\end{array}$

"Unclear risk" of bias

\section{INCOMPLETE OUTCOME DATA}

Criteria for judgment of

"Low risk" of bias

When there was an exhaustive description of

Criteria for judgment of

"High risk" of bias

the main data

If there was a loss due to an incomplete description of the main results regardless of quantity, nature and manipulation

Criteria for judgment of When the results were not reported

"Unclear risk" of bias

\section{SELECTIVE REPORTING}

Criteria for judgment of

"Low risk" of bias

When the discussion excluded some of the

Criteria for judgment of

"High risk" of bias

Criteria for judgment of

"Unclear risk" of bias

\section{results}

When the article discussed the data completely

When the organization of the results in the discussion were unclear

and decision making; the Eriksen flanker task test, which evaluated the reaction time and precision of the response; Visuospatial attention, which assess the reaction time.

\section{Risk of Bias}

The risk of bias in randomized articles was determined based on the Cochrane Collaboration's tool (Figure 2). When evaluated, the "blinding of outcome assessment" was classified as high risk in two studies. For the topics "incomplete outcome data" and "selective reporting" the included articles were classified as low risk. Among the included articles, the article by Tsai et al. (2014) 
TABLE 3 | Criteria for risk assessment of bias according to Methodological Index for Non-Randomized Studies (MINORS) (Slim et al., 2003).

\begin{tabular}{|c|c|}
\hline \multicolumn{2}{|l|}{ CLEARLY STATED AIM } \\
\hline $\begin{array}{l}\text { Criteria for judgment of } \\
\text { "O" of bias }\end{array}$ & When the objectives were not expressed \\
\hline $\begin{array}{l}\text { Criteria for judgment of } \\
\text { "1" of bias }\end{array}$ & $\begin{array}{l}\text { When a clear relationship between the } \\
\text { objectives, results and conclusion was not } \\
\text { found }\end{array}$ \\
\hline $\begin{array}{l}\text { Criteria for judgment of } \\
\text { " } 2 \text { " of bias }\end{array}$ & $\begin{array}{l}\text { When there was a relationship between } \\
\text { the objectives of the article and its results } \\
\text { and conclusions }\end{array}$ \\
\hline \multicolumn{2}{|c|}{ INCLUSION OF CONSECUTIVE PATIENTS } \\
\hline $\begin{array}{l}\text { Criteria for judgment of } \\
\text { " } 0 \text { " of bias }\end{array}$ & When the objectives were not expressed \\
\hline $\begin{array}{l}\text { Criteria for judgment of } \\
\text { "1" of bias }\end{array}$ & $\begin{array}{l}\text { When only the inclusion criteria was } \\
\text { described or when it was not clear how } \\
\text { the sample was selected }\end{array}$ \\
\hline $\begin{array}{l}\text { Criteria for judgment of } \\
\text { " } 2 \text { " of bias }\end{array}$ & $\begin{array}{l}\text { When the terms led to the samples' } \\
\text { inclusion and exclusion and were clearly } \\
\text { described }\end{array}$ \\
\hline \multicolumn{2}{|c|}{ PROSPECTIVE DATA COLLECTION } \\
\hline $\begin{array}{l}\text { Criteria for judgment of } \\
\text { "O" of bias }\end{array}$ & When there was no information reported \\
\hline $\begin{array}{l}\text { Criteria for judgment of } \\
\text { "1" of bias }\end{array}$ & When there were changes \\
\hline $\begin{array}{l}\text { Criteria for judgment of } \\
\text { " } 2 \text { " of bias }\end{array}$ & $\begin{array}{l}\text { When the data collection was already } \\
\text { established at the beginning of the study }\end{array}$ \\
\hline \multicolumn{2}{|c|}{ ENDPOINTS APPROPRIATE TO STUDY AIM } \\
\hline $\begin{array}{l}\text { Criteria for judgment of } \\
\text { " } 0 \text { " of bias }\end{array}$ & When unreported \\
\hline $\begin{array}{l}\text { Criteria for judgment of } \\
\text { "1" of bias }\end{array}$ & $\begin{array}{l}\text { If the techniques were not well explained } \\
\text { or leave doubt regarding the methodology }\end{array}$ \\
\hline $\begin{array}{l}\text { Criteria for judgment of } \\
\text { " } 2 \text { " of bias }\end{array}$ & $\begin{array}{l}\text { If the evaluation techniques are well } \\
\text { explained and were already referenced } \\
\text { and answered the purpose of the study }\end{array}$ \\
\hline \multicolumn{2}{|c|}{ UNBIASED ASSESSMENT OF STUDY ENDPOINT } \\
\hline $\begin{array}{l}\text { Criteria for judgment of } \\
\text { " } 0 \text { " of bias }\end{array}$ & When it was not reported \\
\hline $\begin{array}{l}\text { Criteria for judgment of } \\
\text { "1" of bias }\end{array}$ & $\begin{array}{l}\text { When, due to some limitation, the } \\
\text { methodology was not a blind sample }\end{array}$ \\
\hline $\begin{array}{l}\text { Criteria for judgment of } \\
\text { " } 2 \text { " of bias }\end{array}$ & $\begin{array}{l}\text { If the existence of the double-blind } \\
\text { analysis was described }\end{array}$ \\
\hline \multicolumn{2}{|c|}{ FOLLOW-UP PERIOD APPROPRIATE TO STUDY AIM } \\
\hline $\begin{array}{l}\text { Criteria for judgment of } \\
\text { " } 0 \text { " of bias }\end{array}$ & When the results were unreported \\
\hline $\begin{array}{l}\text { Criteria for judgment of } \\
\text { "1" of bias }\end{array}$ & $\begin{array}{l}\text { When the literature did not provide } \\
\text { information about the training time and the } \\
\text { post-training window }\end{array}$ \\
\hline $\begin{array}{l}\text { Criteria for judgment of } \\
\text { "2" of bias }\end{array}$ & $\begin{array}{l}\text { If the literature referenced the training time } \\
\text { preference and the post-training window }\end{array}$ \\
\hline \multicolumn{2}{|c|}{ LOSS TO FOLLOW UP <5\% } \\
\hline $\begin{array}{l}\text { Criteria for judgment of } \\
\text { " } 0 \text { " of bias }\end{array}$ & When the results were not reported \\
\hline $\begin{array}{l}\text { Criteria for judgment of } \\
\text { "1" of bias }\end{array}$ & $\begin{array}{l}\text { When the loss was higher than } 5 \% \text { and } \\
\text { justified by the study }\end{array}$ \\
\hline $\begin{array}{l}\text { Criteria for judgment of } \\
\text { " } 2 \text { " of bias }\end{array}$ & $\begin{array}{l}\text { When the loss in the sample was reported } \\
\text { as }<5 \%\end{array}$ \\
\hline
\end{tabular}

(Continued)
TABLE 3 | Continued

\section{PROSPECTIVE CALCULATION OF STUDY SIZE}

Criteria for judgment of

When the results were not reported

"O" of bias

Criteria for judgment of When the sample calculation was not

"1" of bias performed, but explained

Criteria for judgment of When the calculation methodology for the "2" of bias definition of the sample was reported

\section{AN ADEQUATE CONTROL GROUP}

Criteria for judgment of

When the criteria was not reported

"O" of bias

Criteria for judgment of

"1" of bias

Criteria for judgment of

"2" of bias

When the criteria for group choice were unclear

If the control group was made up of sedentary, healthy people and the criteria for the group selection was clear

\section{CONTEMPORARY GROUPS}

Criteria for judgment of

"O" of bias

Criteria for judgment of

"1" of bias

When these details were not reported

Criteria for judgment of

"2" of bias

When one of the groups already had a training routine

When the groups started the training together

\section{BASELINE EQUIVALENCE OF GROUPS}

Criteria for judgment of

When these details were not reported

"O" of bias

Criteria for judgment of

"1" of bias

Criteria for judgment of

"2" of bias

When the groups did not have the same demographic characteristics

When the groups had similar demographics

\section{ADEQUATE STATISTICAL ANALYSES}

Criteria for judgment of

When the tests were either unsuitable for

"O" of bias

Criteria for judgment of

"1" of bias the type of study or not reported

Criteria for judgment of

"2" of bias

When the descriptions of the performed tests were not clear

When the test was used according to the type of study and was clearly described

presented the highest index. In contrast, the lowest risk of bias was observed in the article by Olson et al. (2016).

When the article by Bue-Estes et al. (2008) was evaluated (Table 5), it was revealed to be moderate quality with a score of 13 out of a maximum of 24 points (Khan et al., 2015). For the topics "clearly stated aim," "inclusion of consecutive patients," "endpoints appropriate to study aim," "adequate control group," and "baseline equivalence of groups," the study achieved the maximum score (2). The article did not report information for the topics "follow-up period appropriates to study aim," " $<5 \%$ lost to follow-up," "prospective calculation of study size" and "contemporary groups," therefore, these were scored null (0).

\section{DISCUSSION}

This systematic review investigated the effects of moderate physical exercise on cognition. All three studies included in this review (Bue-Estes et al., 2008; Tsai et al., 2014; Olson et al., 2016) concluded that physical exercise seems 


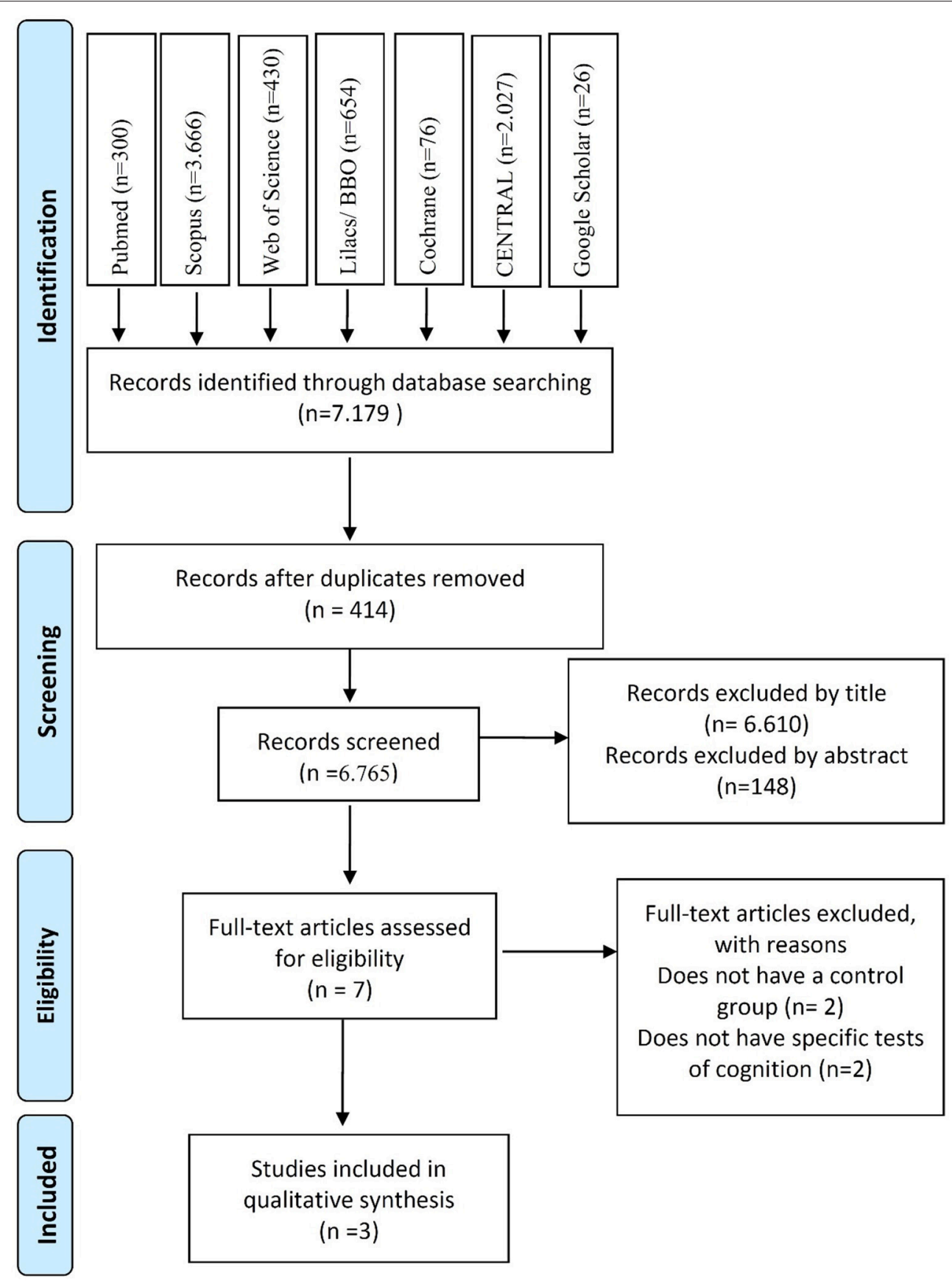

FIGURE 1 | Flow diagram of the literature search according to items in the Preferred Reporting Items for Systematic Review and Meta-Analysis (PRISMA) guideline.

to improve some cognitive parameters in adults, such as simple reaction time, response accuracy and working memory.

The systematic review could be an effective tool to answer specific questions from primary studies on a subject (Cook et al., 1997), in addition to evaluating the quality of the information and the risk of bias in the articles (Sanderson et al., 2007).

In this systematic review, all studies shown an improvement of cognitive parameters related to moderate physical exercise, such as reduced simple reaction time and improved precision of response to a visual motor stimulus and working memory may be related to exercise intensity (Macpherson et al., 2011), which was measured by $\mathrm{VO}_{2}$ max (Bue-Estes et al., 2008; Tsai et al., 2014; Olson et al., 2016). This methodological variable of physical training (intensity) was the same in the three selected articles. In the selected articles, exercise intensity was quantified by the $\mathrm{VO}_{2}$ max test, which is considered a gold standard to quantify exercise intensity and provides a basis for ensuring 


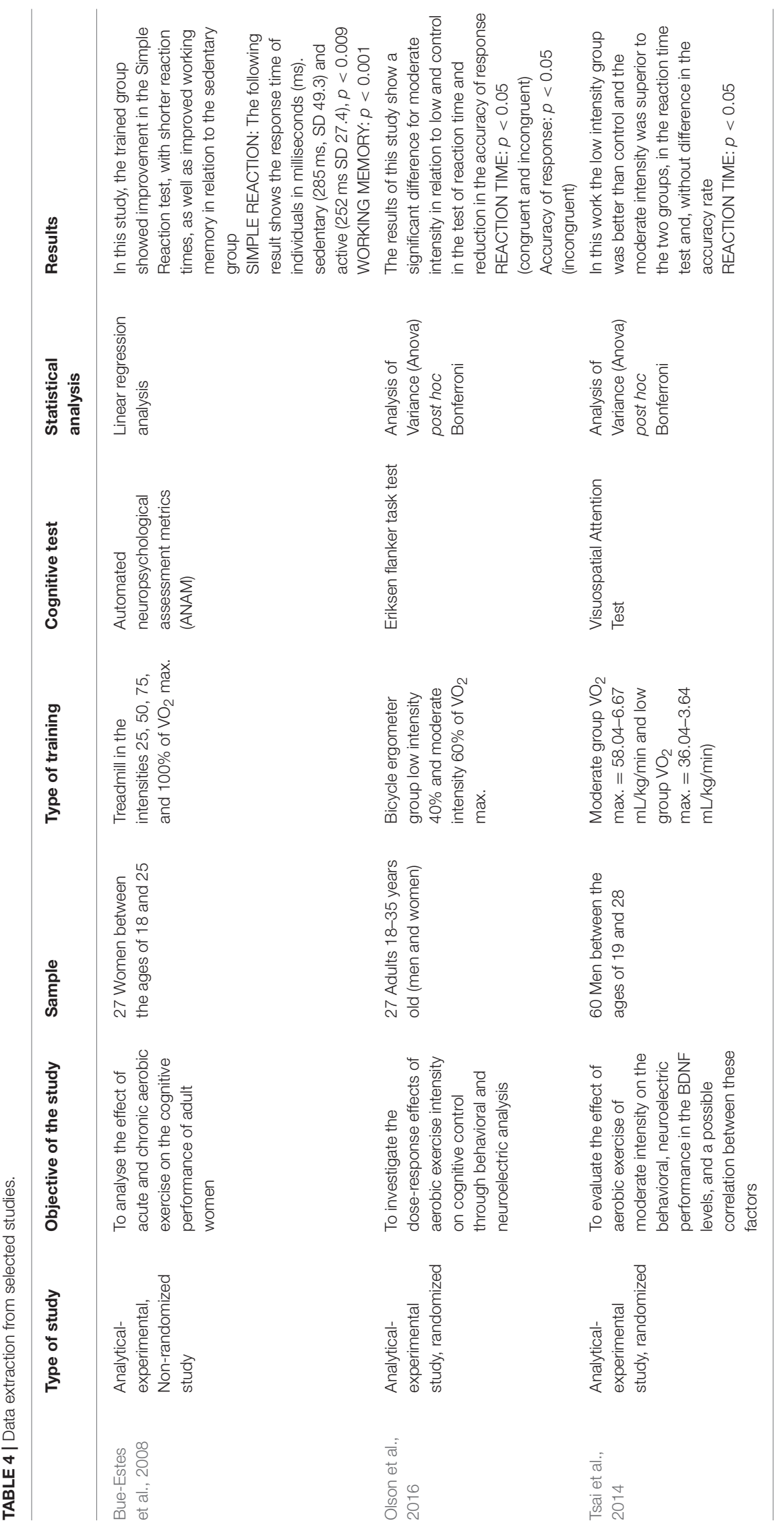


that the obtained results are in accordance by the proposed training.

High-intensity exercise may depress cognitive ability (van den Berg et al., 2016), but moderate-intensity exercise improves this function when the simple reaction time is evaluated (Tsai et al., 2014). On the other hand, studies have shown that sedentary groups who do low-intensity exercise show no difference when compared to sedentary groups (Voss et al., 2011; Olson et al., 2016). The current evident indicates that exercise prescriptions to improve cognition should not be at the extremes of intensity (Voss et al., 2011; Tsai et al., 2014; Olson et al., 2016; van den Berg et al., 2016), and thus should have a linear relationship with this variable, corroborating the findings of this review.

Among the included studies, different forms of exercise performed by individuals from different age groups and both genders, showing similar results on Improvement of cognitive function. This may be related to the characteristics of the exercise performed, which was primarily aerobic in all of the analyzed studies. Quantification of exercise by $\mathrm{VO}_{2} \max$ (Koutlianos et al., 2013) can be used to individually quantify the intensity according to independent physical exercise variables such as the type of exercise, gender and age.

The cognitive improvements reported in the selected articles may be associated with the capacity of moderate exercise to modulate the central nervous system. Aerobic physical exercise is related to elevated levels of orexin-A and orexin-B (Messina et al., 2016), both neuropeptides synthesized in the hypothalamus that increase neurogenesis and connections between hippocampal neurons, especially in the dentate gyrus, an area involved in cognition (Oomen et al., 2014; Chen et al., 2015; Chieffi et al., 2017a; Trinchero et al., 2017). Orexin-A has neuroprotective and anti-apoptotic effects, and is essential for better performance in terms of attention and working memory (Deadwyler et al., 2007).

Orexin-B/hypocretin-2 (OxB/Hcrt-2) increases the expression of BDNF mRNA leading to increased production of BDNF (Chieffi et al., 2017b), a neurotrophic factor which plays an essential role in cognition (Lee et al., 2015). High levels of BDNF in the hippocampal region modulates long-term potentiation and synaptic plasticity, stimulating learning and memory (Nettiksimmons et al., 2014), in addition to increasing working memory in the prefrontal cortex (Yeom et al., 2016).

Another growth factor that is increased with physical exercise is vascular endothelial gowth factor (VEGF), which promotes angiogenesis (Morland et al., 2017) and is directly associated with neurogenesis and improvement of synaptic function. Thus, VEGF can influence cognitive function through neurogenesis, cerebral blood flow and modulation of long-term potentiation; however, the underlying mechanism has not yet been fully elucidated ( $\mathrm{Ng}$ et al., 2014).

New blood vessels formed through angiogenesis are unstable (Darland and D'Amore, 1999). The presence of insulin-like growth factor 1 (IGF-1) is essential as it is responsible for the maturation and stability of these neovessels (Jacobo and Kazlauskas, 2015). It is interesting to note that studies have suggested that physical exercise contributes to stabilizing neovessels due to the associated increase in IGF-1 production

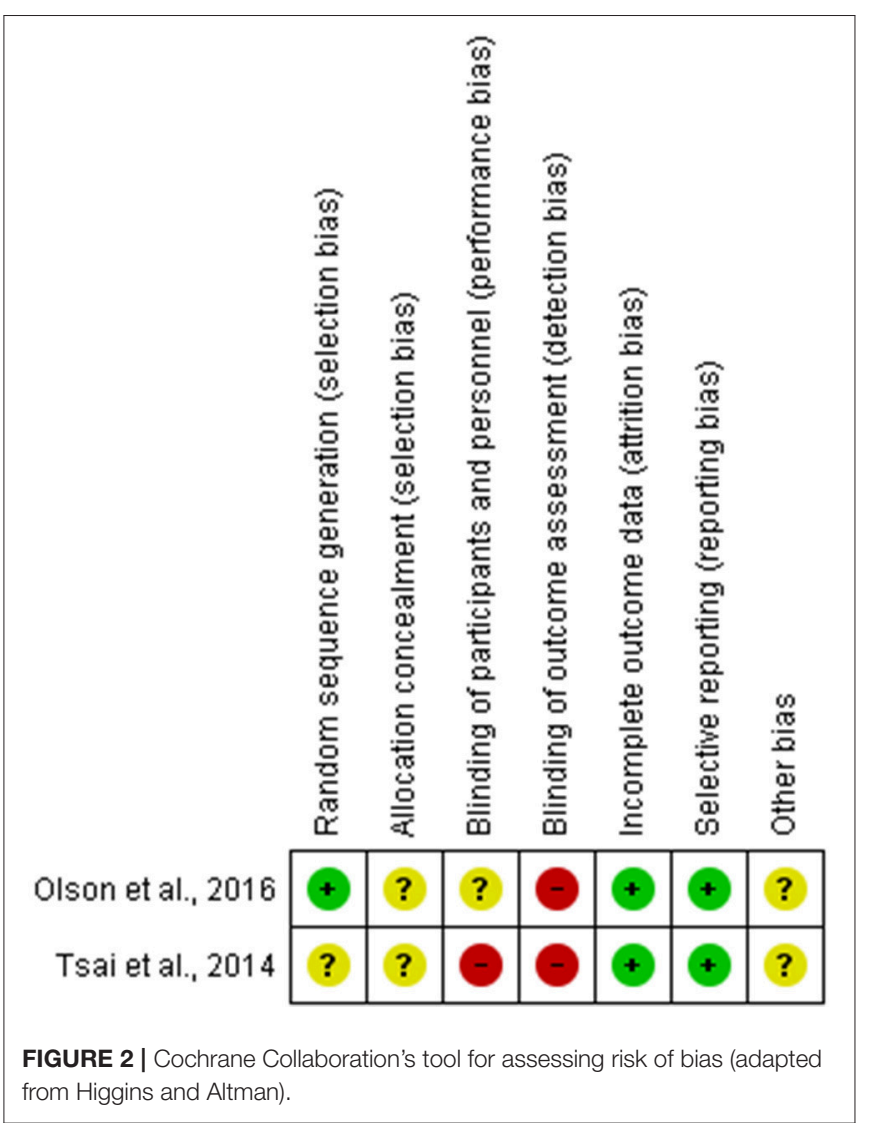

TABLE 5 | Individual MINORS score.

Bue-Estes et al., 2008

Clearly stated aim

2

Inclusion of consecutive patients

2

Prospective data collection

Endpoints appropriate to study aim

1

Unbiased assessment of study endpoint

Follow-up period appropriate to study aim

$<5 \%$ lost to follow-up

Prospective calculation of study size

Adequate control group

Contemporary groups

Baseline equivalence of groups

Adequate statistical analyses

TOTAL

MINORS Quality score

2

1

0

0

0

2

0

2

1

$13 / 24$

$\mathrm{MQ}$

(Carro et al., 2000; Nakamura et al., 2010; Jacobo and Kazlauskas, 2015).

As suggested by studies and animals and humans, the moderate physical exercise is related to an increase in different neutrophins, as well as to the homeostasis and energetic regulation of nervous system (Kerr et al., 2010; Rhyu et al., 2010; Swain et al., 2012; Marosi and Mattson, 2014; Bathina and Das, 
2015; Jacobo and Kazlauskas, 2015; Camerino et al., 2016; Chieffi et al., 2017b,c; Morland et al., 2017). These changes contribute to an increase on plasticity, the formation of new synapses and the integration of neurons to neurons circuits (Gomez-PalacioSchjetnan and Escobar, 2013; Lu et al., 2014; Phillips, 2017). The improvement of cognition is suggested as a result of this modulation (Colicos and Syed, 2006).

Cognition is a set of processes which functions to classify, recognize and understand information by reasoning through learning and executing responses (Vaynman et al., 2004). However, the three chosen articles only evaluated reaction time parameters, working memory and the accuracy of response. Executive function is an example of a higher cognitive process and includes capabilities such as goal setting, planning and executing action plans and effectively performing actions (Jurado and Rosselli, 2007). Cognition can be modulated throughout life under various stimuli, and varies according to educational level (Liu et al., 2017), nutritional quality (Moody et al., 2017), activity of antioxidants (Farah et al., 2016), and the practice of physical exercise (Atherton et al., 2016; Cadenas-Sanchez et al., 2016).

Several tests are available to the functional evaluation of cognitive parameters (Sanders and Lamers, 2002; Stins et al., 2007; Tsoi et al., 2015). Among them, the primary example of these tests are: STROOP Task (Erdodi et al., 2018), Simon Test (Stoet, 2017), Visual Spatial Attention (Tsai et al., 2016; Byun et al., 2017) and Eriksen Flanker Task (Swatridge et al., 2017; Baumgartner et al., 2018). The Visual Spatial Attention and Eriksen Flanker Task were used among the included studies. All of these tests are used to study the interaction between processing speed, executive functions and working memory, important cognitive domains, which allow us to evaluate selective attention ability and ability, as well as planning, decision making and interference management in real world (Zeischka et al., 2010; Chen et al., 2013; Diamond, 2013).

Another test used in one of the included articles (Bue-Estes et al., 2008) is the Automated Neuropsychological Assessment Metrics (ANAM). This tool is composed by computerized cognitive tests and behavioral questionnaires (Vincent et al., 2017). This tool was previoulsy described as a time-cost efficient feature and presenting a moderate sensitivity and a high specificity when compared to traditional neuropsychological tests,(Jones et al., 2008; Xie et al., 2015; Cole et al., 2017; Paech et al., 2017; Vincent et al., 2017).

In the articles included in this review (Bue-Estes et al., 2008; Tsai et al., 2014; Olson et al., 2016), reaction time as a cognitive parameter was found to be improved, as seen in Table 4. This is an important parameter that can help evaluate the speed of information processing (Batra et al., 2015). These processes were analyzed for their speed and accuracy in terms of response (van Ede et al., 2012), thus evidencing a possible association between moderate physical exercise and improvement of the synaptic network integration involved in this action.

Working memory was another altered cognitive parameter described in one of the articles, which is characterized by the ability to reorganize lists, organize thoughts to form meaningful sentences, incorporate new information, consider options and relate ideas and thoughts (Baddeley, 2012). This was only evaluated in one of the studies (Bue-Estes et al., 2008), in which the authors found an improvement in the group that performed moderate physical exercise compared to the control group and the intensity of the moderate physical exercise group, evidencing a specific effect of exercise intensity.

Cognition can be modulated throughout life under various stimuli, and varies according to educational level (Liu et al., 2017), nutritional quality (Moody et al., 2017), activity of antioxidants (Farah et al., 2016) and the practice of physical exercise (Atherton et al., 2016; Cadenas-Sanchez et al., 2016).

To evaluate the methodological soundness on individual studies regarding their validity and risk of bias, two tools were used: the MINORS tool, a non-randomized tool, and the Cochrane collaboration's tool, used for randomized studies. Among the two randomized studies, one was classified as low risk (Olson et al., 2016) and the other as uncertain risk (Tsai et al., 2014), taking into account the critical key domains chosen for this review.

From the MINORS tool, one of the articles was considered moderate quality (Bue-Estes et al., 2008) while the other had a high risk of bias regarding parameters related to blinding. This was not a critical parameter for this review due to its non-viability, as blinding ensures ignorance (study participants, researchers, medical staff, statisticians) regarding the allocation of participants to one group or another (Higgins et al., 2011).

It is also worth mentioning that during the recruitment of individuals, all the included studies reported that they received information about the procedures and purpose of the research (Bue-Estes et al., 2008; Tsai et al., 2014; Olson et al., 2016). Therefore, this was not one of the major domains for evaluating the quality of the articles included in this systematic review as it interferes with the reliability of this information (Higgins et al., 2011).

\section{LIMITATIONS}

Despite the moderate methodological quality and risk of bias of the included articles, moderate physical exercise appears to play a relevant role in the improvement of some cognitive parameters such as simple reaction time, response precision and working memory. However, these are just some of the existing cognitive parameters, and it is important that additional investigations with greater methodological accuracy be carried out by elucidating unexplored parameters in the selected articles.

\section{CONCLUSION}

Practicing moderate physical exercise may improve cognition in individuals who seek to improve their routinely used cognitive functions and for those who want to prevent or delay cognitive decline.

\section{AUTHOR CONTRIBUTIONS}

$\mathrm{RF}$ and MC contributed equally to this work. RF and MC designed the systematic review and supervised the entire 
program. RL, MdS, and LM reviewed all the studies and extracted the information from the eligible trials. NF and AA analyzed the data and prepared the figures and table. RF and MC wrote the paper. RL, MS, and LM revised the manuscript. All authors reviewed and approved the manuscript.

\section{REFERENCES}

American College of Sports Medicine (2009). American College of Sports Medicine position stand. Progression models in resistance training for healthy adults. Med. Sci. Sports Exerc. 41, 687-708. doi: 10.1249/MSS.0b013e3181915670

Atherton, N., Bridle, C., Brown, D., Collins, H., Dosanjh, S., Griffiths, F., et al. (2016). Dementia and Physical Activity (DAPA)-an exercise intervention to improve cognition in people with mild to moderate dementia: study protocol for a randomized controlled trial. Trials 17:165. doi: $10.1186 / \mathrm{s} 13063-016-1288-2$

Avola, R., Di Tullio, M. A., Fisichella, A., Tayebati, S. K., and Tomassoni, D. (2004). Glial fibrillary acidic protein and vimentin expression is regulated by glucocorticoids and neurotrophic factors in primary rat astroglial cultures. Clin. Exp. Hypertens. 26, 323-333. doi: 10.1081/CEH-120034137

Baddeley, A. (2012). Working memory: theories, models, and controversies. Annu. Rev. Psychol. 63, 1-29. doi: 10.1146/annurev-psych-120710-100422

Barstow, T. J., Lamarra, N., and Whipp, B. J. (1990). Modulation of muscle and pulmonary $\mathrm{O}_{2}$ uptakes by circulatory dynamics during exercise. J. Appl. Physiol. 68, 979-989. doi: 10.1152/jappl.1990.68.3.979

Bathina, S., and Das, U. N. (2015). Brain-derived neurotrophic factor and its clinical implications. Arch. Med. Sci. 11, 1164-1178. doi: 10.5114/aoms.2015.56342

Batra, K., Kumar, A., Kumar, V., Nanda, T., Maan, N. S., and Maan, S. (2015). Development and evaluation of loop-mediated isothermal amplification assay for rapid detection of Capripoxvirus. Vet. World 8, 1286-1292. doi: 10.14202/vetworld.2015.1286-1292

Baumgartner, N. W., Walk, A. M., Edwards, C. G., Covello, A. R., Chojnacki, M. R., Reeser, G. E., et al. (2018). Relationship between physical activity, adiposity, and attentional inhibition. J. Phys. Act. Health 15, 191-196. doi: 10.1123/jpah.2017-0181

Best, J. R., Chiu, B. K., Hall, P. A., and Liu-Ambrose, T. (2017). Larger lateral prefrontal cortex volume predicts better exercise adherence among older women: evidence from two exercise training studies. J. Gerontol. A Biol. Sci. Med. Sci. 72, 804-810. doi: 10.1093/gerona/glx043

Biddle, S. J., and Ashford, B. (1988). Cognitions and perceptions of health and exercise. Br. J. Sports Med. 22, 135-140. doi: 10.1136/bjsm.22.4.135

Bonini, M., Fioretti, D., Sargentini, V., Del Giacco, S., Rinaldi, M., Tranquilli, C., et al. (2013). Increased nerve growth factor serum levels in top athletes. Clin. J. Sport Med. 23, 228-231. doi: 10.1097/JSM.0b013e31827ee6d5

Bowden, M. G., Embry, A. E., and Gregory, C. M. (2011). Physical therapy adjuvants to promote optimization of walking recovery after stroke. Stroke Res. Treat. 2011:601416. doi: 10.4061/2011/601416

Braz, I. D., and Fisher, J. P. (2016). The impact of age on cerebral perfusion, oxygenation and metabolism during exercise in humans. J. Physiol. 594, 4471-4483. doi: 10.1113/JP271081

Brown, D. R., Wang, Y., Ward, A., Ebbeling, C. B., Fortlage, L., Puleo, E., et al. (1995). Chronic psychological effects of exercise and exercise plus cognitive strategies. Med. Sci. Sports Exerc. 27, 765-775. doi: 10.1249/00005768-199505000-00021

Bue-Estes, C. L., Willer, B., Burton, H., Leddy, J. J., Wilding, G. E., and Horvath, P. J. (2008). Short-term exercise to exhaustion and its effects on cognitive function in young women. Percept. Mot. Skills 107, 933-945. doi: $10.2466 / \mathrm{pms} .107 .3 .933-945$

Byun, J. I., Lee, B. U., Kim, M., Sunwoo, J. S., Lim, J. A., Moon, J., et al. (2017). Reduced P300 amplitude during a visuospatial attention task in idiopathic rapid eye movement sleep behavior disorder. Sleep Med. 38, 78-84. doi: $10.1016 /$ j.sleep.2017.06.037

Cadenas-Sanchez, C., Mora-Gonzalez, J., Migueles, J. H., Martin-Matillas, M., Gomez-Vida, J., Escolano-Margarit, M. V., et al. (2016). An exercise-based

\section{SUPPLEMENTARY MATERIAL}

The Supplementary Material for this article can be found online at: https://www.frontiersin.org/articles/10.3389/fphys. 2018.00667/full\#supplementary-material

randomized controlled trial on brain, cognition, physical health and mental health in overweight/obese children (ActiveBrains project): rationale, design and methods. Contemp. Clin. Trials 47, 315-324. doi: 10.1016/j.cct.2016.02.007

Camerino, C., Conte, E., Cannone, M., Caloiero, R., Fonzino, A., and Tricarico, D. (2016). Nerve growth factor, brain-derived neurotrophic factor and osteocalcin gene relationship in energy regulation, bone homeostasis and reproductive organs analyzed by mRNA quantitative evaluation and linear correlation analysis. Front. Physiol. 7:456. doi: 10.3389/fphys.2016.00456

Carro, E., Nunez, A., Busiguina, S., and Torres-Aleman, I. (2000). Circulating insulin-like growth factor I mediates effects of exercise on the brain. J. Neurosci. 20, 2926-2933. doi: 10.1523/JNEUROSCI.20-08-02926.2000

Caspersen, C. J., Powell, K. E., and Christenson, G. M. (1985). Physical activity, exercise, and physical fitness: definitions and distinctions for health-related research. Public Health Rep. 100, 126-131.

Chen, A., Tang, D., and Chen, X. (2013). Training reveals the Sources of Stroop and Flanker Interference Effects. PLoS ONE 8:e76580. doi: 10.1371/journal.pone.0076580

Chen, H., Iinuma, M., Onozuka, M., and Kubo, K.-Y. (2015). Chewing maintains hippocampus-dependent cognitive function. Int. J. Med. Sci. 12, 502-509. doi: 10.7150/ijms.11911

Chieffi, S., Carotenuto, M., Monda, V., Valenzano, A., Villano, I., Precenzano, F., et al. (2017a). Orexin system: the key for a healthy life. Front. Physiol. 8:357. doi: 10.3389/fphys.2017.00357

Chieffi, S., Messina, G., Villano, I., Messina, A., Esposito, M., Monda, V., et al. (2017b). Exercise influence on hippocampal function: possible involvement of Orexin-A. Front. Physiol. 8:85. doi: 10.3389/fphys.2017.00085

Chieffi, S., Messina, G., Villano, I., Messina, A., Valenzano, A., Moscatelli, F., et al. $(2017 \mathrm{c})$. Neuroprotective effects of physical activity: evidence from human and animal studies. Front. Physiol. 8:188. doi: 10.3389/fneur.2017. 00188

Coelho, F. G., Vital, T. M., Stein, A. M., Arantes, F. J., Rueda, A. V., Camarini, R., et al. (2014). Acute aerobic exercise increases brain-derived neurotrophic factor levels in elderly with Alzheimer's disease. J. Alzheimers. Dis. 39, 401-408. doi: 10.3233/JAD-131073

Cole, W. R., Gregory, E., Arrieux, J. P., and Haran, F. J. (2017). Intra-individual cognitive variability: an examination of ANAM4 TBI-MIL simple reaction time data from service members with and without mild traumatic brain injury. J. Int. Neuropsychol. Soc. doi: 10.1017/S1355617717000856. [Epub ahead of print].

Colicos, M. A., and Syed, N. I. (2006). Neuronal networks and synaptic plasticity: understanding complex system dynamics by interfacing neurons with silicon technologies. J. Exp. Biol. 209, 2312-2319. doi: 10.1242/jeb.02163

Cook, D. J., Mulrow, C. D., and Haynes, R. B. (1997). Systematic reviews: synthesis of best evidence for clinical decisions. Ann. Intern. Med. 126, 376-380. doi: 10.7326/0003-4819-126-5-199703010-00006

Dalsgaard, M. K., and Secher, N. H. (2007). The brain at work: a cerebral metabolic manifestation of central fatigue? J. Neurosci. Res. 85, 3334-3339. doi: $10.1002 /$ jnr.21274

Darland, D. C., and D'Amore, P. A. (1999). Blood vessel maturation: vascular development comes of age. J. Clin. Invest. 103, 157-158. doi: 10.1172/JCI6127

Deadwyler, S. A., Porrino, L., Siegel, J. M., and Hampson, R. E. (2007). Systemic and nasal delivery of orexin-A (Hypocretin-1) reduces the effects of sleep deprivation on cognitive performance in nonhuman primates. J. Neurosci. 27, 14239-14247. doi: 10.1523/JNEUROSCI.3878-07.2007

Diamond, A. (2013). Executive Functions. Annu. Rev. Psychol. 64, 135-168. doi: 10.1146/annurev-psych-113011-143750

Dietrich, M. O., Andrews, Z. B., and Horvath, T. L. (2008). Exerciseinduced synaptogenesis in the hippocampus is dependent on UCP2regulated mitochondrial adaptation. J. Neurosci. 28, 10766-10771. doi: 10.1523/JNEUROSCI.2744-08.2008 
Douw, L., Nieboer, D., Van Dijk, B. W., Stam, C. J., and Twisk, J. W. R. (2014). A healthy brain in a healthy body: brain network correlates of physical and mental fitness. PLOS ONE 9:e88202. doi: 10.1371/journal.pone.0088202

Drummond, M. J., Vehrs, P. R., Schaalje, G. B., and Parcell, A. C. (2005). Aerobic and resistance exercise sequence affects excess postexercise oxygen consumption. J. Strength Cond. Res. 19, 332-337. doi: 10.1519/R-14353.1

Erdodi, L. A., Sagar, S., Seke, K., Zuccato, B. G., Schwartz, E. S., and Roth, R. M. (2018). The Stroop test as a measure of performance validity in adults clinically referred for neuropsychological assessment. Psychol. Assess. doi: 10.1037/pas0000525. [Epub ahead of print].

Erickson, K. I., Gildengers, A. G., and Butters, M. A. (2013). Physical activity and brain plasticity in late adulthood. Dialogues Clin. Neurosci. 15, 99-108.

Farah, R., Gilbey, P., Grozovski, M., Asli, H., Khamisy-Farah, R., and Assy, N. (2016). Antioxidant enzyme activity and cognition in obese individuals with or without metabolic risk factors. Exp. Clin. Endocrinol. Diabetes 124, 568-571. doi: $10.1055 / \mathrm{s}-0042-113125$

Gomez-Palacio-Schjetnan, A., and Escobar, M. L. (2013). Neurotrophins and synaptic plasticity. Curr. Top. Behav. Neurosci. 15, 117-136. doi: 10.1007/7854_2012_231

Hashimoto, T., Tsukamoto, H., Takenaka, S., Olesen, N. D., Petersen, L. G., Sorensen, H., et al. (2018). Maintained exercise-enhanced brain executive function related to cerebral lactate metabolism in men. FASEB J. 32, 1417-1427. doi: 10.1096/fj.201700381RR

Higgins, J. P. T., Altman, D. G., Gøtzsche, P. C., Jüni, P., Moher, D., Oxman, A. D., et al. (2011). The cochrane collaboration's tool for assessing risk of bias in randomised trials. BMJ 343:d5928. doi: 10.1136/bmj.d5928

Jacobo, S. M., and Kazlauskas, A. (2015). Insulin-like growth factor 1 (IGF-1) stabilizes nascent blood vessels. J. Biol. Chem. 290, 6349-6360. doi: 10.1074/jbc.M114.634154

Jones, W. P., Loe, S. A., Krach, S. K., Rager, R. Y., and Jones, H. M. (2008). Automated neuropsychological assessment metrics (Anam) and WoodcockJohnson III tests of cognitive ability: a concurrent validity study. Clin. Neuropsychol. 22, 305-320. doi: 10.1080/13854040701281483

Jurado, M. B., and Rosselli, M. (2007). The elusive nature of executive functions: a review of our current understanding. Neuropsychol. Rev. 17, 213-233. doi: $10.1007 / \mathrm{s} 11065-007-9040-\mathrm{z}$

Kerr, A. L., Steuer, E. L., Pochtarev, V., and Swain, R. A. (2010). Angiogenesis but not neurogenesis is critical for normal learning and memory acquisition. Neuroscience 171, 214-226. doi: 10.1016/j.neuroscience.2010.08.008

Khan, W., Khan, M., Alradwan, H., Williams, R., Simunovic, N., and Ayeni, O. R. (2015). Utility of intra-articular hip injections for femoroacetabular impingement: a systematic review. Orthop. J. Sports Med. 3:2325967115601030. doi: $10.1177 / 2325967115601030$

Koutlianos, N., Dimitros, E., Metaxas, T., Cansiz, M., Deligiannis, A. S., and Kouidi, E. (2013). Indirect estimation of VOmax in athletes by ACSM's equation: valid or not? Hippokratia 17, 136-140.

Lee, J. K. W., Ang, W. H., Ng, J. W. X., Fan, P. W. P., Teo, Y. S., Nolte, H. W., et al. (2014). Effects of a carbohydrate-electrolyte solution on cognitive performance following exercise-induced hyperthermia in humans. J. Int. Soc. Sports Nutr. 11:51. doi: 10.1186/s12970-014-0051-x

Lee, S. J., Baek, J.-H., and Kim, Y.-H. (2015). Brain-derived neurotrophic factor is associated with cognitive impairment in elderly korean individuals. Clin. Psychopharmacol. Neurosci. 13, 283-287. doi: 10.9758/cpn.2015. 13.3.283

Liu, Y. C., Liu, Y. Y., Yip, P. K., Meguro, M., and Meguro, K. (2017). Speaking one more language in early life has only minor effects on cognition in Taiwanese with low education level: the Taishan Project. Psychogeriatrics 17, 256-261. doi: 10.1111 psyg. 12230

Lu, B., Nagappan, G., and Lu, Y. (2014). BDNF and synaptic plasticity, cognitive function, and dysfunction. Handb. Exp. Pharmacol. 220, 223-250. doi: 10.1007/978-3-642-45106-5_9

Macpherson, R. E., Hazell, T. J., Olver, T. D., Paterson, D. H., and Lemon, P. W. (2011). Run sprint interval training improves aerobic performance but not maximal cardiac output. Med. Sci. Sports Exerc. 43, 115-122. doi: 10.1249/MSS.0b013e3181e5eacd

Marosi, K., and Mattson, M. P. (2014). BDNF mediates adaptive brain and body responses to energetic challenges. Trends Endocrinol. Metab. 25, 89-98. doi: $10.1016 /$ j.tem.2013.10.006
Messina, G., Di Bernardo, G., Viggiano, A., De Luca, V., Monda, V., Messina, A., et al. (2016). Exercise increases the level of plasma orexin A in humans. J. Basic Clin. Physiol. Pharmacol. 27, 611-616. doi: 10.1515/jbcpp-2015-0133

Moher, D., Liberati, A., Tetzlaff, J., Altman, D. G., and Group, P. (2009). Preferred reporting items for systematic reviews and meta-analyses: the PRISMA statement. PLoS Med. 6:e1000097. doi: 10.1371/journal.pmed.1000097

Moody, L., Chen, H., and Pan, Y. X. (2017). Early-life nutritional programming of cognition-the fundamental role of epigenetic mechanisms in mediating the relation between early-life environment and learning and memory process. Adv. Nutr. 8, 337-350. doi: 10.3945/an.116.014209

Moon, C. M., Yang, J. C., and Jeong, G. W. (2017). Functional neuroanatomy associated with the interaction between emotion and cognition in explicit memory tasks in patients with generalized anxiety disorder. Acta Radiol. 58, 98-106. doi: 10.1177/0284185116633915

Morland, C., Andersson, K. A., Haugen, Ø. P., Hadzic, A., Kleppa, L., Gille, A., et al. (2017). Exercise induces cerebral VEGF and angiogenesis via the lactate receptor HCAR1. Nat. Commun. 8:15557. doi: 10.1038/ncomms15557

Morris, J. N., and Crawford, M. D. (1958). Coronary heart disease and physical activity of work. Br. Med. J. 2, 1485-1496. doi: 10.1136/bmj.2. 5111.1485

Nakamura, K., Sasajima, J., Mizukami, Y., Sugiyama, Y., Yamazaki, M., Fujii, R., et al. (2010). Hedgehog promotes neovascularization in pancreatic cancers by regulating Ang-1 and IGF-1 expression in bone-marrow derived proangiogenic cells. PLoS ONE 5:e8824. doi: 10.1371/journal.pone.0008824

Nettiksimmons, J., Simonsick, E. M., Harris, T., Satterfield, S., Rosano, C., Yaffe, K., et al. (2014). The associations between serum brain-derived neurotrophic factor, potential confounders, and cognitive decline: a longitudinal study. PLoS ONE 9:e91339. doi: 10.1371/journal.pone.0091339

Ng, T., Cheung, Y. T., Ng, Q. S., Ho, H. K., and Chan, A. (2014). Vascular endothelial growth factor inhibitors and cognitive impairment: evidence and controversies. Expert Opin. Drug Saf. 13, 83-92. doi: 10.1517/14740338.2013.828034

Nielsen, H. B., Boushel, R., Madsen, P., and Secher, N. H. (1999). Cerebral desaturation during exercise reversed by $\mathrm{O}_{2}$ supplementation. Am. J. Physiol. 277(3 Pt 2), H1045-H1052. doi: 10.1152/ajpheart.1999.277.3.H1045

Olson, R. L., Chang, Y. K., Brush, C. J., Kwok, A. N., Gordon, V. X., and Alderman, B. L. (2016). Neurophysiological and behavioral correlates of cognitive control during low and moderate intensity exercise. Neuroimage 131, 171-180. doi: 10.1016/j.neuroimage.2015.10.011

Oomen, C. A., Bekinschtein, P., Kent, B. A., Saksida, L. M., and Bussey, T. J. (2014). Adult hippocampal neurogenesis and its role in cognition. Wiley Interdiscip. Rev. Cogn. Sci. 5, 573-587. doi: 10.1002/wcs.1304

Paech, G. M., Crowley, S. J., and Eastman, C. I. (2017). Sleep and cognitive performance of African-Americans and European-Americans before and during circadian misalignment produced by an abrupt 9-h delay in the sleep/wake schedule. PLoS ONE 12:e0186843. doi: 10.1371/journal.pone.0186843

Phillips, C. (2017). Brain-derived neurotrophic factor, depression, and physical activity: making the neuroplastic connection. Neural Plast. 2017:7260130. doi: $10.1155 / 2017 / 7260130$

Rhyu, I. J., Bytheway, J. A., Kohler, S. J., Lange, H., Lee, K. J., Boklewski, J., et al. (2010). Effects of aerobic exercise training on cognitive function and cortical vascularity in monkeys. Neuroscience 167, 1239-1248. doi: 10.1016/j.neuroscience.2010.03.003

Rooks, C. R., Thom, N. J., McCully, K. K., and Dishman, R. K. (2010). Effects of incremental exercise on cerebral oxygenation measured by nearinfrared spectroscopy: a systematic review. Prog. Neurobiol. 92, 134-150. doi: 10.1016/j.pneurobio.2010.06.002

Sanders, A. F., and Lamers, J. M. (2002). The Eriksen flanker effect revisited. Acta Psychol. 109, 41-56. doi: 10.1016/S0001-6918(01)00048-8

Sanderson, S., Tatt, I. D., and Higgins, J. P. (2007). Tools for assessing quality and susceptibility to bias in observational studies in epidemiology: a systematic review and annotated bibliography. Int. J. Epidemiol. 36, 666-676. doi: 10.1093/ije/dym018

Seifert, T., Fisher, J. P., Young, C. N., Hartwich, D., Ogoh, S., Raven, P. B., et al. (2010). Glycopyrrolate abolishes the exercise-induced increase in cerebral perfusion in humans. Exp. Physiol. 95, 1016-1025. doi: 10.1113/expphysiol.2010.054346 
Slim, K., Nini, E., Forestier, D., Kwiatkowski, F., Panis, Y., and Chipponi, J. (2003). Methodological index for non-randomized studies (minors): development and validation of a new instrument. ANZ J. Surg. 73, 712-716. doi: 10.1046/j.1445-2197.2003.02748.x

Stins, J. F., Polderman, J. C. T., Boomsma, D. I., and de Geus, E. J. C. (2007). Conditional accuracy in response interference tasks: evidence from the eriksen flanker task and the spatial conflict task. Adv. Cogn. Psychol. 3, 409-417. doi: 10.2478/v10053-008-0005-4

Stoet, G. (2017). Sex differences in the Simon task help to interpret sex differences in selective attention. Psychol. Res. 81, 571-581. doi: 10.1007/s00426-016-0763-4

Swain, R. A., Berggren, K. L., Kerr, A. L., Patel, A., Peplinski, C., and Sikorski, A. M. (2012). On aerobic exercise and behavioral and neural plasticity. Brain Sci. 2, 709-744. doi: 10.3390/brainsci2040709

Swatridge, K., Regan, K., Staines, W. R., Roy, E., and Middleton, L. E. (2017). The acute effects of aerobic exercise on cognitive control among people with Chronic Stroke. J. Stroke Cerebrovasc. Dis. 26, 2742-2748. doi: 10.1016/j.jstrokecerebrovasdis.2017.06.050

Trinchero, M. F., Buttner, K. A., Sulkes Cuevas, J. N., Temprana, S. G., Fontanet, P. A., Monzón-Salinas, M. C., et al. (2017). High plasticity of new granule cells in the aging Hippocampus. Cell Rep. 21, 1129-1139. doi: 10.1016/j.celrep.2017.09.064

Tsai, C.-L., Chen, F.-C., Pan, C.-Y., and Tseng, Y.-T. (2016). The neurocognitive performance of visuospatial attention in children with obesity. Front. Psychol. 7:1033. doi: 10.3389/fpsyg.2016.01033

Tsai, C. L., Chen, F. C., Pan, C. Y., Wang, C. H., Huang, T. H., and Chen, T. C. (2014). Impact of acute aerobic exercise and cardiorespiratory fitness on visuospatial attention performance and serum BDNF levels. Psychoneuroendocrinology 41, 121-131. doi: 10.1016/j.psyneuen.2013.12.014

Tsoi, K. K., Chan, J. Y., Hirai, H. W., Wong, S. Y., and Kwok, T. C. (2015). Cognitive tests to detect dementia: a systematic review and meta-analysis. JAMA Intern. Med. 175, 1450-1458. doi: 10.1001/jamainternmed.2015.2152

Tucker, A. M., and Stern, Y. (2011). Cognitive reserve in aging. Curr. Alzheimer Res. 8, 354-360. doi: 10.2174/156720511795745320

Tyler, W. J., and Pozzo-Miller, L. (2003). Miniature synaptic transmission and BDNF modulate dendritic spine growth and form in rat CA1 neurones. $J$. Physiol. 553(Pt 2), 497-509. doi: 10.1113/jphysiol.2003.052639

van den Berg, V., Saliasi, E., de Groot, R. H., Jolles, J., Chinapaw, M. J., and Singh, A. S. (2016). Physical activity in the school setting: cognitive performance is not affected by three different types of acute exercise. Front. Psychol. 7:723. doi: 10.3389/fpsyg.2016.00723 van Ede, F., de Lange, F. P., and Maris, E. (2012). Attentional cues affect accuracy and reaction time via different cognitive and neural processes. J. Neurosci. 32, 10408-10412. doi: 10.1523/JNEUROSCI.1337-12.2012

van Hall, G., Stromstad, M., Rasmussen, P., Jans, O., Zaar, M., Gam, C., et al. (2009). Blood lactate is an important energy source for the human brain. J. Cereb. Blood Flow Metab. 29, 1121-1129. doi: 10.1038/jcbfm.2009.35

Vaynman, S., Ying, Z., and Gomez-Pinilla, F. (2004). Hippocampal BDNF mediates the efficacy of exercise on synaptic plasticity and cognition. Eur. J. Neurosci. 20, 2580-2590. doi: 10.1111/j.1460-9568.2004.03720.x

Vincent, A. S., Roebuck-Spencer, T. M., Cox-Fuenzalida, L. E., Block, C., Scott, J. G., and Kane, R. (2017). Validation of ANAM for cognitive screening in a mixed clinical sample. Appl. Neuropsychol. Adult 25, 366-375. doi: 10.1080/23279095.2017.1314967

Voss, M. W., Nagamatsu, L. S., Liu-Ambrose, T., and Kramer, A. F. (2011). Exercise, brain, and cognition across the life span. J. Appl. Physiol. 111, 1505-1513. doi: 10.1152/japplphysiol.00210.2011

Xie, S. S., Goldstein, C. M., Gathright, E. C., Gunstad, J., Dolansky, M. A., Redle, J., et al. (2015). Performance of the Automated Neuropsychological Assessment Metrics (ANAM) in detecting cognitive impairment in heart failure patients. Heart Lung J. Crit. Care 44, 387-394. doi: 10.1016/j.hrtlng.2015. 07.002

Yeom, C.-W., Park, Y.-J., Choi, S.-W., and Bhang, S.-Y. (2016). Association of peripheral BDNF level with cognition, attention and behavior in preschool children. Child Adolesc. Psychiatry Ment. Health 10:10. doi: 10.1186/s13034-016-0097-4

Zeischka, P., Deroost, N., Henderickx, D., and Soetens, E. (2010). Testing the attention shift hypothesis as an account for the flanker sequence-based congruency modulation in spatial flanker tasks. Am. J. Psychol. 123, 337-351. doi: 10.5406/amerjpsyc.123.3.0337

Conflict of Interest Statement: The authors declare that the research was conducted in the absence of any commercial or financial relationships that could be construed as a potential conflict of interest.

Copyright (C) 2018 Fernandes, Correa, dos Santos, Almeida, Fagundes, Maia and Lima. This is an open-access article distributed under the terms of the Creative Commons Attribution License (CC BY). The use, distribution or reproduction in other forums is permitted, provided the original author(s) and the copyright owner are credited and that the original publication in this journal is cited, in accordance with accepted academic practice. No use, distribution or reproduction is permitted which does not comply with these terms. 